Dokuz Eylül Üniversitesi-Mühendislik Fakültesi

Fen ve Mühendislik Dergisi

Cilt 20, Sayı 59, Mayıs, 2018
Dokuz Eylul University-Faculty of Engineering Journal of Science and Engineering Volume 20, Issue 59, May, 2018

DOI: $10.21205 /$ deufmd. 2018205944

\title{
Dokuma Kumaşlarda Ultrasonik Dikiş Üzerine Bir Araştırma
}

\author{
Ayşe ŞEVKAN MACiT' ${ }^{* 1}$, Bahar TIBBER ${ }^{2}$
}

${ }^{1}$ Uşak Üniversitesi, Mühendislik Fakültesi, Tekstil Mühendisliği Bölümü, 64200, Uşak (ORCID: 0000-0002-0646-8582)

2Uşak Üniversitesi, Mühendislik Fakültesi, Tekstil Mühendisliği Bölümü, 64200, Uşak

(ORCID: 0000-0001-7145-9327)

(Alınış / Received: 13.10.2017, Kabul / Accepted: 08.12.2017,

Online Yayınlanma / Published Online: 15.05.2018)

Anahtar Kelimeler Özet: Ultrasonik dikiș yöntemi, farklı tekstil yüzeylerinin nihai Ultrasonik Dikiş, Dikiş

Mukavemeti, Kumaş Sertliği ürüne dönüştürülmesinde kullanılan konvansiyonel dikiş yöntemlerinin alternatiflerinden biridir ve bu yöntem son yıllarda üzerinde durulan bir konu haline gelmiștir. Çalışmada, iğne ve iplik kullanılmadan gerçekleștirilen bu alternatif yöntemle dikilmiş kumaşların dikiş mukavemeti, patlama mukavemeti ve eğilme özelliklerini incelemek üzere poliüretan kaplı üç tip dokuma kumaş kullanılmıştır. Kumaşlar çeşitli parametrelerle birlikte ultrasonik ve konvansiyonel olarak birleștirilmiștir. Her iki yöntemle dikilmiș olan kumașlara yıkama ișlemi uygulanmıș ve yıkama öncesi ve yıkama sonrası kumaşların bahsedilen özellikleri test edilmiştir. Elde edilen sonuçlar, dikiş tipi, kumaş tipi, ultrasonik dikiş hızı ve kaplamanın bulunduğu kısım açısından değerlendirilmiş ve istatistiksel olarak analiz edilmiştir.

\section{An Investigation on Ultrasonic Seaming in Woven Fabrics}

\section{Keywords} Ultrasonic Seam, Seam Strength, Fabric Stiffness
Abstract: Ultrasonic seaming method is one of the alternatives to conventional seaming methods used to convert different textile surfaces into final products and this method has become a subject that has been deliberated in recent years. In the study, three types of polyurethane coated woven fabrics were used to investigate the seam strength, bursting strength and bending properties of the fabrics sewn with this alternative method, which was carried out without the use of needle and yarn. Fabrics were sewn ultrasonically and conventionally with various parameters. The sewn fabrics in both methods were washed and the properties of the fabrics were tested before and after washing process. The results were evaluated in terms of seam type, fabric type, ultrasonic seaming velocity and position of the coating and they were statistically analyzed. 


\section{Giriş}

Konfeksiyon sektörü ülkemizde katma değeri artıran büyük öneme sahip sektörlerden biridir. Bu sektör kadınerkek-çocuk iç ve diş giyimde, ev tekstilinde ve teknik tekstiller alanında faaliyet göstermektedir. $\mathrm{Bu}$ alanlarda farklı yöntemlerle üretilen değișik kumaș yüzeylerinin nihai ürün haline dönüştürülmesinde çeşitli dikiş yöntemleri kullanılmaktadır. Sıkça kullanılan konvansiyonel dikiş yöntemlerinin yanı sıra alternatif dikiş yöntemlerine de ihtiyaç duyulmaktadır. Ultrasonik dikiş yöntemi, son ylllarda dikkat çeken ve üzerinde çalışılan alternatif dikiş yöntemlerinden biridir.

Ultrasonik, insan kulağının duyamayacağı düzeyde ya da yaklaşık 20 $\mathrm{kHz}$ in üzerindeki frekanslardaki ses dalgaları olarak tanımlanır [1]. Ultrasonik birleştirme işleminin esası, termoplastik yapıdaki materyalleri birleștirmek amacıyla yüksek frekansta titreşimi kullanmaya dayanır. Titreşim sonucu materyalde ısı artışı oluşur, bu ısı artıșıyla materyal eriyip birleşir ve bir bağ oluşturur [2].

Ultrasonik dikiș, enerji tasarrufu sağlayan bir yöntem olmakla birlikte konvansiyonel dikiş yöntemlerinde kullanılan iplik gibi materyallere ihtiyaç duyulmadı̆̆ı için geri dönüșümü de daha kolay olan bir yöntem olarak görülmektedir [3].

Ultrasonik birleștirme yöntemi otomotiv, tekstil, konfeksiyon, medikal, ambalaj, elektronik, filtrasyon gibi farklı endüstri dallarında kullanılmaktadır. Tekstil endüstrisinde ultrasonik enerji çeşitli işlemlerde yer almakla beraber ilk kez şilte bezi ve yatak örtüleri oluşturmak için kullanılmıştır ve günümüzde tekstil yüzeylerini ve film yüzeylerini dikmek, kesmek, şekil vermek ve bunları ürün haline dönüştürmek için kullanılan önemli bir yöntemdir [2].
Son yıllarda ultrasonik dikişle ilgili yapılan birçok çalışma mevcuttur. Konuyla ilgili yapılan çalışmalarda ultrasonik dikiş ve konvansiyonel dikişle dikilmiş kumaşların çeşitli özellikleri incelenmiştir.

Vujasinovic ve arkadaşlarının (2007) yelken kumaşı kullanarak yaptığı bir çalışmada konvansiyonel dikiş ve ultrasonik dikiş yöntemleri, dikiş mukavemeti ve hava geçirgenliği özellikleri incelenerek karşılaştırılmıştır. Uygun örs tipi, optimum titreşim genliği ve hız ile uygulandığında ultrasonik dikişin klasik dikişin yerini alabileceği, uygun kaynak parametrelerinin yelkenin dikiș mukavemetini artırdığı gibi hava geçirgenliği de sağladığı belirtilmiştir [4].

Appleby (2009) poliester kumaş kullanarak konvansiyonel dikiş ile ultrasonik dikişi, dikiş mukavemeti ve kumaş sertliği açısından karşılaştırmıştır. Ultrasonik dikişin dikiş mukavemetinin konvansiyonel dikișe göre daha düșük çıktı̆̆ı belirtilmiştir [1]. Yine bu iki yöntemin dikiş mukavemeti açısından karşılaştırıldığı çeşitli çalışmalarda, ultrasonik dikișin daha düșük dikiș mukavemeti gösterdiği belirtilmiştir [3, 5, 6]. Appleby tarafindan yapılan çalışmada ultrasonik dikişin kumaş sertliğinin konvansiyonel dikișe göre daha yüksek çıktığı belirtilmiştir ve bu sonucun desteklendiği farklı çalışmalar da mevcuttur $[6,7]$.

Boz ve Erdoğan'ın (2011) yaptı̆̆ çalışmada SMS ve spunbond kumaş tipi kullanılarak konvansiyonel dikiș ile ultrasonik dikiş, dikiş mukavemeti açısından karşılaştırılmış, iki farklı örs tipinde gerçekleștirilen ultrasonik dikișin konvansiyonel dikişe göre daha yüksek dikiş mukavemeti gösterdiği ve ultrasonik dikişin işlem süresi açısından da konvansiyonel dikişe göre daha avantajlı olduğu belirtilmiștir [8]. 
Yapılan bu çalışmada poliüretan kaphı farklı örgü yapısı ve gramajda üç tip dokuma kumaş kullanılmıştır. PU kaplama, kumaşların tek tarafında bulunmaktadır. Kumaşlar hem konvansiyonel olarak hem de ultrasonik olarak birleştirilmiştir. Ultrasonik dikiş kaplamanın iç ve dıș kısımda bulunmasına göre ve iki farklı hızda gerçekleștirilmiștir. Her iki yöntemle dikilmiş olan kumaşlar yıkamaya tabi tutulmuş olup yıkama öncesinde ve yıkama sonrasında dikiş mukavemeti ve eğilme davranışı açısından karşılaştırılmışlardır. Eğilme rijitliği kumaş sertliği ile ilişkili bir özelliktir ve kumaş sertliği arttıkça eğilme dayanımı da artmaktadır [9]. Bunun yanı sıra dikiş mukavemeti özelliği kumaşların tek yönde kuvvete maruz bırakıldığı andaki davranışını göstermektedir. Ultrasonik dikişin aynı anda farklı yönlerden gelen kuvvetlere maruz bırakıldığı durumdaki davranışını görmek için ultrasonik dikiş ile dikilmiş kumaşların patlama mukavemetleri de ölçülmüştür. Test sonuçları, dikiş tipine göre kıyaslanmanın yanında; kumaş tipi, ultrasonik dikiş hızı ve kaplamanın bulunduğu kısım açısından da değerlendirilmiş ve istatistiksel olarak analiz edilmiștir.

\section{Materyal ve Metot}

Çalışmada mont olarak kullanım alanı bulan poliüretan kaplı üç farklı dokuma kumaş kullanılmıştır. Kullanılan kumaşların özellikleri Tablo 1'de verilmiștir. Bu kumaşlar Tablo 2'de belirtildiği şekilde farklı dikiş parametrelerine göre ultrasonik ve konvansiyonel olarak dikilerek 15 farklı tipte dikilmiş kumaş numuneleri elde edilmiştir.

Tablo 1. Çalışmada kullanılan kumaşların özellikleri.

\begin{tabular}{ccccc} 
Kumaş kodu & Örgü yapısı & Gramaj $\left(\mathrm{g} / \mathrm{m}^{2}\right)$ & Kalınlık $(\mathrm{mm})$ & Hammadde \\
\hline $\mathrm{D}_{1}$ & Bezayağı & 105 & 0,366 & Poliester \\
$\mathrm{D}_{2}$ & Bezayağı & 170 & 0,432 & Poliester \\
$\mathrm{D}_{3}$ & 2/1 Dimi & 170 & 0,540 & Poliester
\end{tabular}

Tablo 2. Çalışmada uygulanan dikiş parametreleri.

\begin{tabular}{|c|c|c|c|c|}
\hline $\begin{array}{l}\text { Dikilmiş kumaş } \\
\text { kodu }\end{array}$ & Kumaş kodu & Dikiş tipi & Hız kodu & $\begin{array}{c}\text { Kaplama yönü } \\
\text { kodu }\end{array}$ \\
\hline $\mathrm{D}_{1} \mathrm{~V}_{1} / \mathrm{k}_{\mathrm{iç}}$ & $\mathrm{D}_{1}$ & Ultrasonik dikiş & $\mathrm{V}_{1}$ & $\mathrm{k}_{\mathrm{iç}}$ \\
\hline $\mathrm{D}_{1} \mathrm{v}_{2} / \mathrm{k}_{\mathrm{iç}}$ & $\mathrm{D}_{1}$ & Ultrasonik dikiş & $\mathrm{V}_{2}$ & $\mathrm{k}_{\mathrm{iç}}$ \\
\hline $\mathrm{D}_{1} \mathrm{v}_{1} / \mathrm{k}_{\mathrm{d} ı s}$ & $\mathrm{D}_{1}$ & Ultrasonik dikiş & $\mathrm{V}_{1}$ & $\mathrm{k}_{\text {dıș }}$ \\
\hline $\mathrm{D}_{1} \mathrm{~V}_{2} / \mathrm{k}_{\mathrm{d} ı \mathrm{~s}}$ & $\mathrm{D}_{1}$ & Ultrasonik dikiş & V2 & $\mathrm{k}_{\mathrm{d} ı s ̦}$ \\
\hline $\mathrm{D}_{2} \mathrm{v}_{1} / \mathrm{k}_{\mathrm{iç}}$ & $\mathrm{D}_{2}$ & Ultrasonik dikiş & $\mathrm{V}_{1}$ & $\mathrm{k}_{\text {iç }}$ \\
\hline $\mathrm{D}_{2} \mathrm{~V}_{2} / \mathrm{k}_{\mathrm{iç}}$ & $\mathrm{D}_{2}$ & Ultrasonik dikiş & V2 & $\mathrm{k}_{\text {iç }}$ \\
\hline $\mathrm{D}_{2} \mathrm{~V}_{1} / \mathrm{k}_{\mathrm{d} ı s}$ & $\mathrm{D}_{2}$ & Ultrasonik dikiş & $\mathrm{V} 1$ & $\mathrm{k}_{\mathrm{d} ı s ̧}$ \\
\hline $\mathrm{D}_{2} \mathrm{~V}_{2} / \mathrm{k}_{\mathrm{d} ı s}$ & $\mathrm{D}_{2}$ & Ultrasonik dikiş & $\mathrm{V}_{2}$ & $\mathrm{k}_{\text {dıș }}$ \\
\hline $\mathrm{D}_{3} \mathrm{~V}_{1} / \mathrm{k}_{\mathrm{iç}}$ & $\mathrm{D}_{3}$ & Ultrasonik dikiş & $\mathrm{V}_{1}$ & $\mathrm{k}_{\text {iç }}$ \\
\hline $\mathrm{D}_{3} \mathrm{v}_{2} / \mathrm{k}_{\mathrm{iç}}$ & $\mathrm{D}_{3}$ & Ultrasonik dikiş & $\mathrm{V}_{2}$ & $\mathrm{k}_{\text {iç }}$ \\
\hline $\mathrm{D}_{3 \mathrm{~V}} 1 / \mathrm{k}_{\mathrm{d} ı \mathrm{~s}}$ & $\mathrm{D}_{3}$ & Ultrasonik dikiş & $\mathrm{V}_{1}$ & $\mathrm{k}_{\mathrm{d} \text { lş }}$ \\
\hline $\mathrm{D}_{3} \mathrm{~V}_{2} / \mathrm{k}_{\mathrm{d} ı s}$ & $\mathrm{D}_{3}$ & Ultrasonik dikiş & $\mathrm{V} 2$ & kdış \\
\hline$D_{1} 301$ & $\mathrm{D}_{1}$ & 301 tipi dikiş & - & $\mathrm{k}_{\mathrm{d} ı s ̧}$ \\
\hline$D_{2} 301$ & $\mathrm{D}_{2}$ & 301 tipi dikiş & - & $\mathrm{k}_{\mathrm{d} ı s ̧}$ \\
\hline$D_{3} 301$ & $\mathrm{D}_{3}$ & 301 tipi dikiș & - & $\mathrm{k}_{\mathrm{d} ı s}$ \\
\hline
\end{tabular}


Kumaş numuneleri çözgü yönünde hazırlanmış ve dikiş işlemlerine tabi tutulmuștur. Ultrasonik dikiş işlemi Pfaff Seamsonic 8310 ultrasonik dikiş makinesinde $\% 100$ ultrason şiddetinde, $25 \mathrm{dm} / \mathrm{dk}\left(\mathrm{v}_{1}\right)$ ve $45 \mathrm{dm} / \mathrm{dk}\left(\mathrm{v}_{2}\right)$ olmak üzere iki farklı dikiş hızında gerçekleștirilmiștir. Kaplama yönünün ultrasonik dikișe etkisinin araştırılması amacıyla kumaşlar hem kaplanmış yüzeylerinin birbirine bakacağ ${ }^{\prime}\left(\mathrm{k}_{\text {iç}}\right)$ şekilde hem de kaplama olmayan yüzeylerinin birbirine bakacağı (kdış) şekilde ultrasonik dikiş işlemine tabi tutulmuştur. Dikiş işleminde kullanılan 8 $\mathrm{mm}$ genişliğindeki örs tipi Şekil 1'de gösterilmektedir.

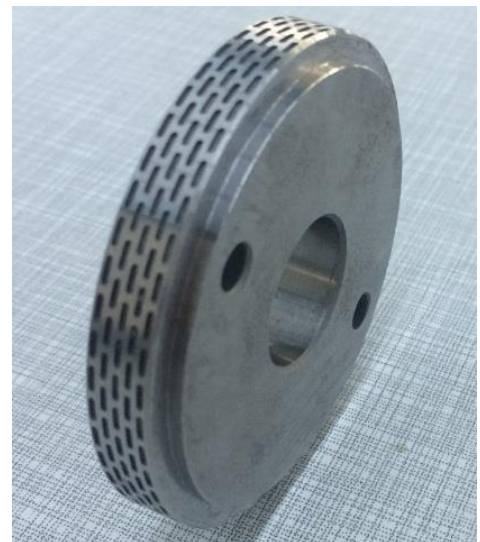

Şekil 1. Ultrasonik dikiş işleminde kullanılan örs tipi.

Konvansiyonel dikiș ișlemleri Brother S7200C-403 model düz dikiş makinesinde 2,6 dikiş/cm sılı̆ğında gerçekleştirilmiştir. Dikiş işlemlerinde 90 $\mathrm{Nm}$ iğne ve $150 \mathrm{dtex} 2$ poliester dikiş ipliği kullanılmıștır. Dikiş işlemi tamamlanmış kumaşlar ev tipi yıkama makinesinde TS EN ISO 6330:2012'ye göre beş tekrarlı yıkama işlemine tabi tutulmuştur [10]. $30^{\circ} \mathrm{C}$ 'de, ön yıkamasız sentetik yıkama programında gerçekleştirilmiş olan yıkama işlemlerinde, $4 \mathrm{~g} / \mathrm{lt}$. fosfatsız ve optik parlatıcı içermeyen ECE referans test deterjanı kullanılmıştır.
Yıkanmamış ve 5 kez yıkanmış numuneler standart atmosfer şartlarında 24 saat kondisyonlandiktan sonra $\left(20 \pm 2^{\circ} \mathrm{C}\right.$ sicaklık ve $\% 65 \pm 2$ bağıl nem) dikiş mukavemeti, patlama mukavemeti ve eğilme testlerine tabi tutulmuştur.

\subsection{Dikiş mukavemeti testi}

Ultrasonik ve konvansiyonel dikiş yöntemleriyle çözgü yönünde dikilmiş kumaşların yıkama öncesi ve yıkama sonrası numuneleri kondisyonlandıktan sonra TS EN ISO 13935-1:2014'e göre, Profi X6 model UTEST çekme cihazında dikiş mukavemeti testine tabi tutulmuştur [11]. Kumaşlardan 350x700 $\mathrm{mm}$ boyutlarında numune alınıp, uzun kenar boyunca ortasından katlanarak dikiş payı $2 \mathrm{~cm}$ olacak şekilde dikilmiştir. Dikilen bu kumaştan $100 \mathrm{~mm}$ genişliğinde beș adet deney numunesi kesilerek hazırlanmıștır. Dikișten $10 \mathrm{~mm}$ uzaklıkta olmak üzere dikilmiş olan her bir numunenin her iki uzun kenarından iç kısma doğru $25 \mathrm{~mm}$ uzunluğunda dört kesik oluşturulmuş ve kumaşın kenarından başlayarak bu kesiklerin bitimine kadar olan kısımlar çıkarılmıştır (Şekil 2). Dikişli bölgesi $100 \mathrm{~mm}$ genişliğinde olan ve $50 \mathrm{~mm}$ 'lik etkin numune enine sahip olan kumaşlar teste hazır hale getirilmiștir. Test sonunda elde edilen mukavemet değerlerinin ortalaması alınarak dikiş mukavemeti değeri (N) belirlenmiştir.

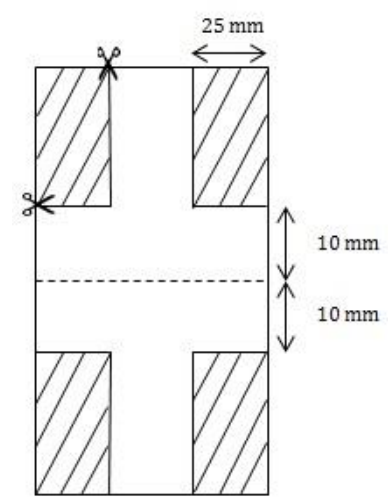

Şekil 2. Dikiş mukavemeti test numunesi. 


\subsection{Patlama mukavemeti testi}

Ultrasonik ve konvansiyonel dikiş yöntemleriyle çözgü yönünde dikilmiş kumaşların yıkama öncesi ve yıkama sonrası numuneleri kondisyonlandıktan sonra TS 393 EN ISO 13938-1:2002'ye göre, M229 model SDL Atlas test cihazında beş tekrarlı șekilde patlama mukavemeti testine tabi tutulmuștur [12]. Test işlemi, numunelerin dikişli bölgeleri 30,5 mm deney alanının tam ortasına yerleşecek șekilde gerçekleștirilmiştir. Test sonunda elde edilen basınç değerlerinin ortalaması alınarak patlama mukavemeti değeri $(\mathrm{kPa})$ belirlenmiștir

\subsection{Eğilme rijitliği testi}

Her iki yöntemle çözgü yönünde dikilmiş olan kumaşların yıkama öncesi ve yıkama sonrası numuneleri kondisyonlandıktan sonra eğilme rijitliği testi TS 1409:1973 standardına uygun şekilde tasarlanmış eğilme rijitliği test cihazında gerçekleştirilmiştir [13]. Dikilmiş kumaş tiplerinin her birinden dikiş ortalanacak şekilde 2,5x15 cm boyutlarında beşer adet numune hazırlanmıştır (Şekil 3). Numuneler her iki uç ve her iki yüzden test edilmiş, her numune için 4 sarkma uzunluğu ve her bir dikilmiş kumaş tipi için ise 20 sarkma uzunluğu elde edilmiştir. Eğilme uzunluğu değerleri Formül 1'de belirtildiği üzere sarkma uzunluğu değerlerinin ortalaması ikiye bölünerek tespit edilmiştir.

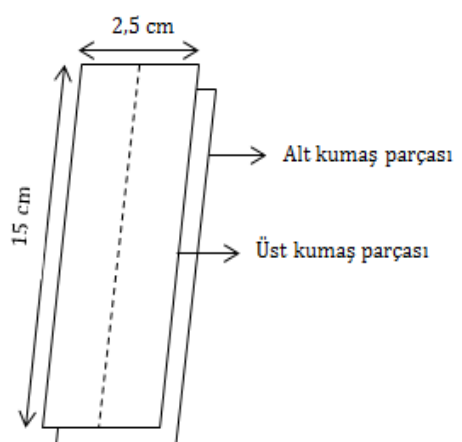

Şekil 3. Eğilme rijitliği test numunesi.
TS 1409:1973'e göre atkı veya çözgü yönünde eğilme rijitliği değeri tek katlı dikilmemiş bir kumaş için altta belirtilen formüle göre hesaplanmaktadır.

$G=0,1 W C^{3} \mathrm{mg} . \mathrm{cm}$

Burada,

$\mathrm{X}=$ Sarkma uzunluğu $(\mathrm{cm})$

$\mathrm{C}=\mathrm{X} / 2=$ Eğilme uzunluğu $(\mathrm{cm})$

$\mathrm{W}=$ Numunenin $\mathrm{m}^{2}$ ağırlığ $\left(\mathrm{g} / \mathrm{m}^{2}\right)$

$\mathrm{G}=$ Eğilme rijitliği (mg.cm)

Çalışmada dikilmiş halde bulunan iki katlı kumaş numuneleri test edildiği için eğilme uzunluğu üzerinden klyaslama yapılmıştır.

Test işlemlerinin ardından elde edilen bulgular, SPSS 13.0 programı yardımıyla tek yönlü varyans analizi (ANOVA) yaplarak istatistiksel olarak değerlendirilmiștir.

\section{Bulgular}

\subsection{Dikis mukavemeti bulguları}

Konvansiyonel ve ultrasonik dikiș yöntemleriyle dikilmiş kumaşların yıkama öncesi ve yıkama sonrası dikiş mukavemeti değerleri Tablo 3 ve Tablo 4'te sırasılyla verilmiștir.

Tablo 3. Konvansiyonel olarak dikilmiş kumaşların yıkama öncesi ve yıkama sonrası dikiş mukavemeti değerleri (N)

\begin{tabular}{|c|c|c|}
\hline \multirow{2}{*}{ Kumaş } & \multicolumn{2}{|c|}{ Kaplama dışarıda } \\
\cline { 2 - 3 } & $\begin{array}{c}\text { Yıkama } \\
\text { öncesi }\end{array}$ & $\begin{array}{c}\text { Yıkama } \\
\text { sonrası }\end{array}$ \\
\hline D1 & 170,08 & 166,22 \\
\hline D2 & 146,84 & 138,86 \\
\hline D3 & 175,28 & 146,48 \\
\hline
\end{tabular}


Tablo 4. Ultrasonik olarak dikilmiş kumaşların yıkama öncesi ve yıkama sonrası dikiş mukavemeti değerleri $(\mathrm{N})$.

\begin{tabular}{|c|c|c|c|c|c|c|c|c|}
\hline \multirow{2}{*}{ Kumaş } & \multicolumn{4}{|c|}{ Kaplama içeride } & \multicolumn{3}{c|}{ Kaplama dişarıda } \\
\cline { 2 - 9 } & \multicolumn{2}{|c|}{ V1 } & \multicolumn{2}{c|}{ V2 } & \multicolumn{2}{c|}{ V1 } & \multicolumn{2}{c|}{ V2 } \\
\cline { 2 - 9 } & $\begin{array}{c}\text { Ylkama } \\
\text { öncesi }\end{array}$ & $\begin{array}{c}\text { Ylkama } \\
\text { sonrası }\end{array}$ & $\begin{array}{c}\text { Ylkama } \\
\text { öncesi }\end{array}$ & $\begin{array}{c}\text { Ylkama } \\
\text { sonrası }\end{array}$ & $\begin{array}{c}\text { Ylkama } \\
\text { onncesi }\end{array}$ & $\begin{array}{c}\text { Ylkama } \\
\text { sonrası }\end{array}$ & $\begin{array}{c}\text { Ylkama } \\
\text { onncesi }\end{array}$ & $\begin{array}{c}\text { Ylkama } \\
\text { sonrası }\end{array}$ \\
\hline D1 & 34,14 & 28,30 & 29,92 & 27,20 & 24,70 & 27,20 & 30,30 & 20,32 \\
\hline D2 & 45,14 & 44,06 & 44,28 & 41,96 & 60,36 & 66,86 & 50,50 & 54,12 \\
\hline D3 & 60,62 & 50,68 & 50,92 & 42,36 & 76,22 & 64,60 & 64,14 & 65,36 \\
\hline
\end{tabular}

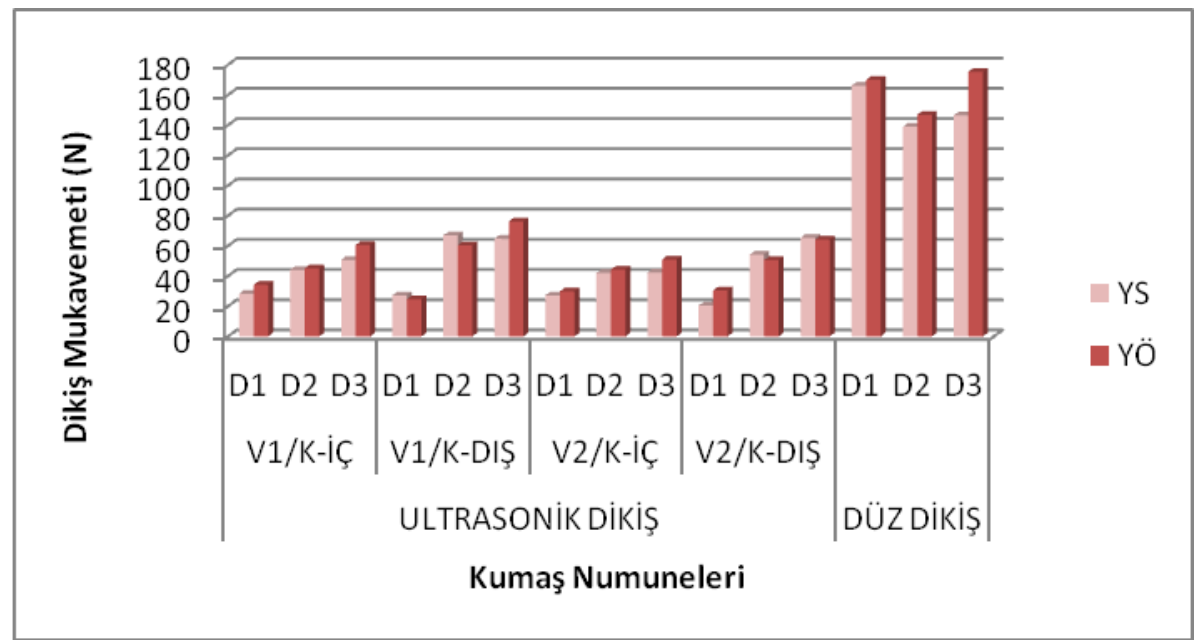

Şekil 4. Ultrasonik ve konvansiyonel olarak dikilmiş kumașların yıkama öncesi ve yıkama sonrası dikiş mukavemeti değerleri $(\mathrm{N})$.

Elde edilen dikiş mukavemeti değerlerine genel olarak bakıldığında (Şekil 4); ultrasonik ve konvansiyonel olarak dikilmiş numunelerde yıkama sonrası dikiș mukavemeti değerlerinin yıkama öncesi dikiş mukavemeti değerlerine göre beklenildiği gibi daha düşük olduğu gözlenmiştir.

Ultrasonik olarak dikilmiş numunelerin dikiş mukavemeti değerlerinin konvansiyonel olarak dikilmiş olanların dikiș mukavemeti değerlerine göre daha düşük seyrettiği ve düşük hızda gerçekleştirilen dikişlerin bulunduğu numunelerin dikiş mukavemeti değerlerinin yüksek hızdakilere göre beklenildiği üzere daha yüksek çıktığı belirlenmiștir. Düşük hızlarda dikiş mukavemeti artışı, bu numunelerin ultrasonik etkiye maruz kalma sürelerinin artmasiyla açıklanabilmektedir.

Ultrasonik dikiş için, gramajı daha yüksek olan D2 ve D3 kumaşlarında kaplamanın dıș kısımda bulunduğu numunelerde dikiş mukavemeti değerlerinin kaplamanın iç kısımda bulunduğu kumaşların değerlerine göre daha yüksek olduğu, daha düşük gramajlı olan D1 kumaşında ise kaplamanın yönüne göre düzenli bir değişim olmadığı görülmüștür. Ultrasonik dikişte hem yıkama öncesi hem de yıkama sonrası dikiş mukavemeti değerlerinin D1, D2 ve D3 kumașlarında sırasıyla artıș gösterdiği, konvansiyonel dikiş için böyle 
bir genellemenin yapılamadığ görülmüștür. Ultrasonik dikişte görülen bu siralama beklenen șekilde gerçekleșmiş, düşük gramajda daha düşük dikiş mukavemeti gözlenmiş, diğer yandan aynı gramajda daha uzun bağlantılara sahip olan dimi örgü yapısında bezayağı örgü yapısından daha yüksek dikiş mukavemeti değerleri gözlenmiştir.
Dikiş tipi ve kaplama yönünün dikiş mukavemeti değerleri üzerindeki etkisinin istatistiksel olarak önemli olduğu belirlenmiştir.

\subsection{Patlama mukavemeti bulguları}

Ultrasonik dikiş yöntemiyle dikilmiş kumașların yıkama öncesi ve yıkama sonrası patlama mukavemeti değerleri Tablo 5'te verilmiştir.

Tablo 5. Ultrasonik olarak dikilmiş kumaşların yıkama öncesi ve yıkama sonrası patlama mukavemeti değerleri ( $\mathrm{kPa})$.

\begin{tabular}{|c|c|c|c|c|c|c|c|c|}
\hline \multirow{2}{*}{ Kumaş } & \multicolumn{4}{|c|}{ Kaplama içeride } & \multicolumn{3}{c|}{ Kaplama dışarıda } \\
\cline { 2 - 9 } & \multicolumn{2}{|c|}{ V1 } & \multicolumn{2}{c|}{ V2 } & \multicolumn{2}{c|}{ V1 } & \multicolumn{2}{c|}{ V2 } \\
\cline { 2 - 9 } & $\begin{array}{c}\text { Yıkama } \\
\text { öncesi }\end{array}$ & $\begin{array}{c}\text { Yıkama } \\
\text { sonrası }\end{array}$ & $\begin{array}{c}\text { Ylkama } \\
\text { öncesi }\end{array}$ & $\begin{array}{c}\text { Ylkama } \\
\text { sonrası }\end{array}$ & $\begin{array}{c}\text { Ylkama } \\
\text { öncesi }\end{array}$ & $\begin{array}{c}\text { Ylkama } \\
\text { sonrası }\end{array}$ & $\begin{array}{c}\text { Ylkama } \\
\text { öncesi }\end{array}$ & $\begin{array}{c}\text { Ylkama } \\
\text { sonrası }\end{array}$ \\
\hline D1 & 108,8 & 97,5 & 143,4 & 122 & 103,5 & 95,6 & 416,3 & 357,9 \\
\hline D2 & 135,7 & 117,6 & 156,4 & 142,7 & - & - & 252 & 189,6 \\
\hline D3 & 184,4 & 182 & 549,2 & 249,6 & 225,1 & - & 526,8 & 335 \\
\hline
\end{tabular}

* - ile belirtilen kumaşlarda ölçüm sonucu elde edilememiştir.

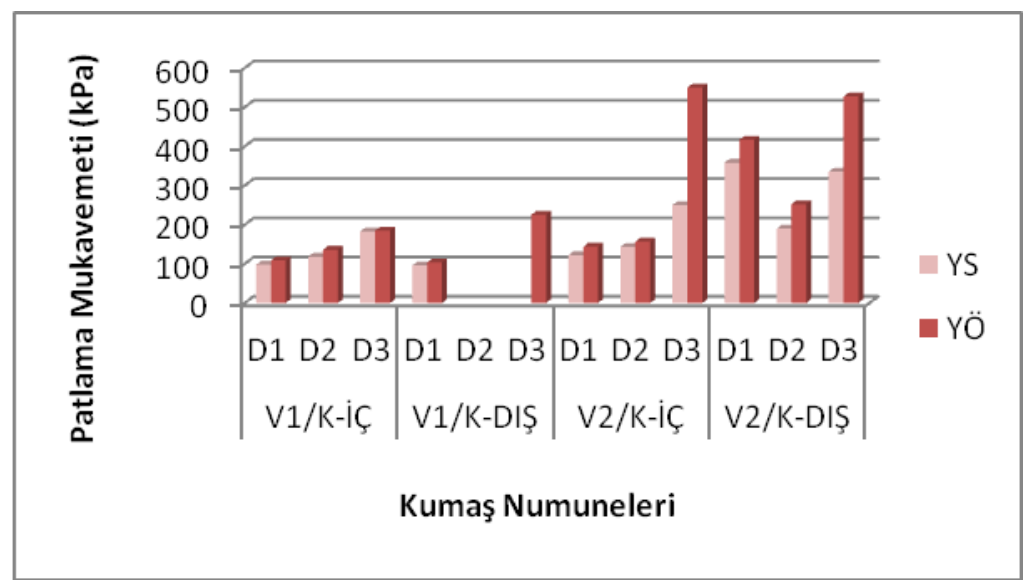

Şekil 5. Ultrasonik olarak dikilmiş kumaşların yıkama öncesi ve yıkama sonrası patlama mukavemeti değerleri $(\mathrm{kPa})$.

Elde edilen patlama mukavemeti değerlerine genel olarak bakıldığında (Şekil 5); ultrasonik dikiş ile dikilmiş numunelerde yıkama sonrası patlama mukavemeti değerlerinin yıkama öncesi patlama mukavemeti değerlerine göre daha düşük olduğu gözlenmiştir.
Ultrasonik dikiș ile dikilmiș numunelerin patlama mukavemeti değerlerinin kaplama yönüne göre düzenli bir değişim göstermediği ve bu kumaşlarda düşük hızda gerçekleştirilen dikişlerin bulunduğu numunelerin patlama mukavemeti değerlerinin yüksek hızdakilere göre daha düşük çıktığı gözlenmiştir. Düşük hızda daha düşük 
patlama mukavemeti değerleri görülmesinin, bu hızda gerçekleştirilen bazı dikiş numunelerinde ultrasonik dikişin üniform șekilde seyretmemesine bağlı olabileceği düşünülmektedir.

Kaplamanın iç kısımda olduğu durumda, patlama mukavemeti değerlerinin D1, D2 ve D3 numunelerinde beklenen şekilde sırasıyla artış gösterdiği, kaplamanın dış kısımda olduğu durumda bu genellemenin yapılamadığı gözlenmiştir.

Yıkama işlemi, kumaş tipi, dikiş hızı ve kaplama yönünün patlama mukavemeti değerleri üzerindeki etkisinin istatistiksel olarak önemli olduğu belirlenmiştir.

\subsection{Eğilme uzunluğu bulguları}

Ultrasonik ve konvansiyonel dikiş yöntemleriyle dikilmiş kumaşların yıkama öncesi ve yıkama sonrası eğilme uzunluğu değerleri Tablo 6 ve Tablo 7'de sırasıyla verilmiştir.

Tablo 6. Ultrasonik olarak dikilmis kumaşların yıkama öncesi ve yıkama sonrası eğilme uzunluğu değerleri $(\mathrm{cm})$.

\begin{tabular}{|c|c|c|c|c|}
\hline \multirow{2}{*}{ Kumaş } & \multicolumn{3}{|c|}{ Kaplama dışarıda } \\
\cline { 2 - 5 } & \multicolumn{2}{|c|}{ V1 } & \multicolumn{2}{c|}{ V2 } \\
\cline { 2 - 5 } & $\begin{array}{c}\text { Ylkama } \\
\text { öncesi }\end{array}$ & $\begin{array}{c}\text { Yıkama } \\
\text { sonrası }\end{array}$ & $\begin{array}{c}\text { Yıkama } \\
\text { öncesi }\end{array}$ & $\begin{array}{c}\text { Yıkama } \\
\text { sonrası }\end{array}$ \\
\hline D1 & 4,84 & 3,83 & 3,96 & 3,61 \\
\hline D2 & 6,48 & 4,81 & 6,03 & 4,56 \\
\hline D3 & 6,5 & 4,6 & 5,1 & 5 \\
\hline
\end{tabular}

Tablo 7. Konvansiyonel olarak dikilmiş kumaşların yıkama öncesi ve yıkama sonrası eğilme uzunluğu değerleri (cm).

\begin{tabular}{|c|c|c|}
\hline \multirow{2}{*}{ Kumaş } & \multicolumn{2}{|c|}{ Kaplama dişarıda } \\
\cline { 2 - 3 } & $\begin{array}{c}\text { Yıkama } \\
\text { öncesi }\end{array}$ & $\begin{array}{c}\text { Yıkama } \\
\text { sonrası }\end{array}$ \\
\hline D1 & 3,03 & 2,92 \\
\hline D2 & 3,28 & 3,2 \\
\hline D3 & 3,72 & 3,62 \\
\hline
\end{tabular}

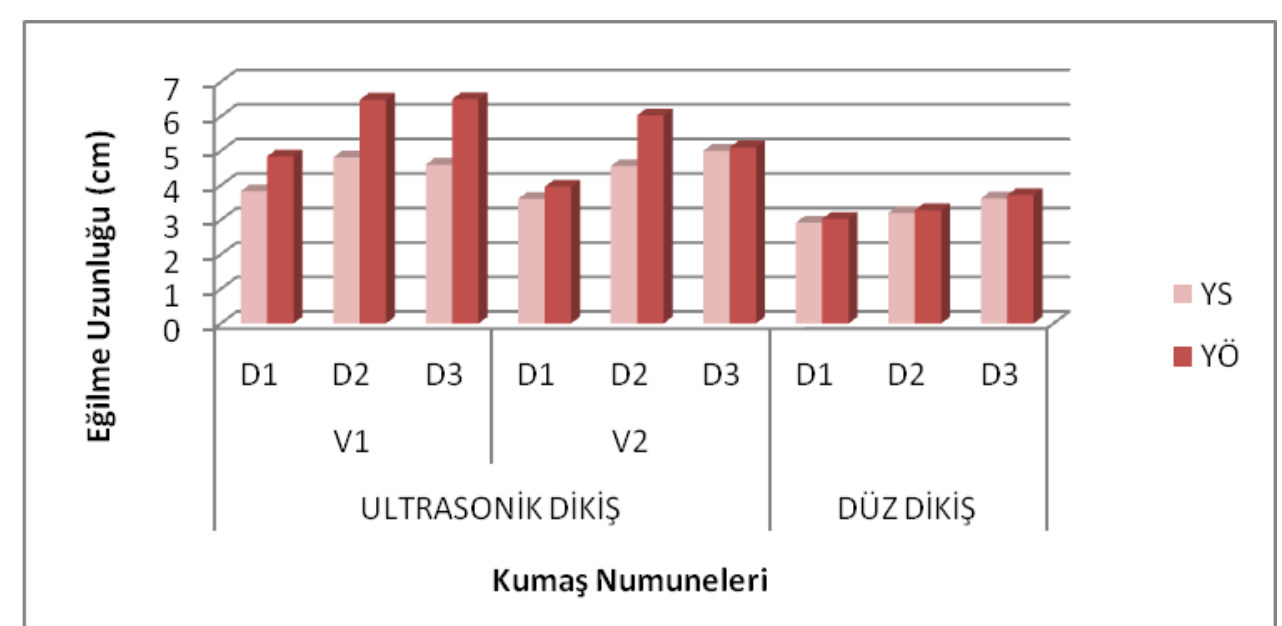

Şekil 6. Ultrasonik ve konvansiyonel olarak dikilmiş kumaşların yıkama öncesi ve yıkama sonrası eğilme uzunluğu değerleri $(\mathrm{cm})$.

Elde edilen eğilme uzunluğu değerlerine genel olarak bakıldığında (Şekil 6); ultrasonik ve konvansiyonel olarak dikilmiş numunelerde yıkama sonrası eğilme uzunluğu değerlerinin yıkama öncesi eğilme uzunluğu değerlerine göre daha düşük seyrettiği gözlenmiştir.
Ultrasonik olarak dikilmiş numunelerin eğilme uzunluğu değerlerinin konvansiyonel olarak dikilmiş olanların değerlerinden daha yüksek olduğu, düşük hızda gerçekleştirilen dikişlerin bulunduğu numunelerin genel olarak yüksek hızdakilere göre beklenildiği üzere daha yüksek eğilme uzunluğu değerleri gösterdiği belirlenmiştir. 
Eğilme uzunluğu değerlerinin konvansiyonel dikiş tipi için D1, D2 ve D3 numunelerinde beklenildiği üzere sırasıyla artış gösterdiği, ultrasonik dikiş tipi için de en düşük eğilme uzunluğu değerlerinin D1 kumaşında gözlendiği belirlenmiștir.

Yıkama işlemi, dikiș tipi ve kumaș tipinin eğilme uzunluğu değerleri üzerindeki etkisinin istatistiksel olarak önemli olduğu belirlenmiştir.

\section{Sonuçlar}

Çalışmada poliüretan kaplı üç farklı dokuma kumaşa ultrasonik ve konvansiyonel dikiş uygulanmış ve on beș tipte dikilmiş kumaş elde edilerek bu kumașların dikiș mukavemeti, patlama mukavemeti ve eğilme özellikleri incelenmiştir. Yıkama işlemi, kumaş tipi, dikiş tipi, dikiş hızı ve kaplama yönünün bu özellikler üzerindeki etkileri gözlemlenmiştir. Çalışmanın bulgularına göre genel olarak aşağıdaki sonuçlar elde edilmiştir:

- Yıkama işleminin beklenildiği üzere dikiş mukavemeti, patlama mukavemeti ve eğilme uzunluğu değerlerini düşürücü etkisi olduğu görülmüştür.

- Dikiş tipine bakıldığında, ultrasonik dikişte eğilme uzunluğu değerlerinin daha yüksek, dikiş mukavemeti değerlerinin daha düşük olduğu gözlenmiștir.

- Ultrasonik dikiște hız artışının dikiș mukavemeti ve eğilme uzunluğu değerlerini düşürücü etkisi olduğu belirlenmiștir.

- Ultrasonik dikişte, kaplamanın içte ya da dışta olması, gramajı yüksek olan kumaşlarda dikiş mukavemetini etkileyici bir rol oynamıştır; bu kumaşlarda kaplamanın diş kısımda bulunduğu numunelerin dikiş mukavemeti değerlerinin kaplama içte bulunanlara göre daha yüksek olduğu gözlenmiş ve gramajı düşük olan kumaşta ise kaplamanın yönüne göre bir genelleme yapılamadığ belirlenmiștir. Patlama mukavemeti değerlerinin ise kaplamanın bulunduğu kısma göre düzenli bir değişim göstermediği görülmüştür.

- Dikiş mukavemeti, patlama mukavemeti ve eğilme uzunluğu değerlerinin kumaş tipinden etkilendiği görülmüștür.

Ultrasonik dikiş, hem kullanım kolaylığı, hem hızlı birleştirme süreci hem de iğne, iplik gibi üretim materyallerine ihtiyaç duymaması açısından avantajlı bir birleştirme yöntemi olarak çeşitli sektörlerde yer almaktadır. Sonuçlara genel olarak bakıldığında, ultrasonik dikiş yönteminin yüksek mukavemetin gerekli olmadığı ve kumaş sertliğinin yüksek olmasının avantaj olabileceği yerlerde optimum kumaş yapısı ve uygun üretim parametreleri belirlenerek daha fazla kullanım alanı bulabileceği düşünülmektedir.

\section{Teşekkür}

Yazarlar, ultrasonik dikiş makinesi kullanımındaki desteklerinden dolayı Prof. Dr. M. Çetin ERDOĞAN ve Öğr. Gör. Dr. Serkan BOZ'a teşekkürlerini sunar.

$\mathrm{Bu}$ çalıșma Ușak Üniversitesi Bilimsel Araştırma Projeleri Koordinasyon Birimince desteklenmiştir. Proje Numarası: 2015/MF005.

\section{Kaynakça}

[1] Appleby, C. K., 2009. Development Of Fabric Seaming For Clothing Using Ultrasonic Sealing Technique, Lisans Bitirme Tezi, Eastern Michigan University, Michigan.

[2] Yeşilpınar, S., Bahar, S., 2005. Ultrasonik Dikiș Makinaları, Tekstil Maraton, Yll 15, Sayı 80, 9-17.

[3] Ghosh, S., Reddy, R. K., 2009. Ultrasonic Sealing of Polyester and Spectra Fabrics Using Thermo Plastic Properties, Journal of Applied 
Polymer Science, Vol. 113, 10821089.

[4] Vujasinović, E., Janković, Z., Dragčević, Z., Petrunić, I., Rogale, D., 2007. Investigation of the strength of ultrasonically welded sails, International journal of clothing science and technology, 19(3), 204214.

[5] Boles, K., 2012. Ultrasonic Examination of Alternative Fabric Joining Techniques Compared To Traditional Sewing, Mc Nair Scholars Research Journal, vol. 5, Iss: 1, Article 3.

[6] Jevšnik, S., Eryürük, S. H., Kalaoğlu, F., Kayaoğlu, B. K., Komarkova, P., Golombikova, V., Stjepanovič, Z., 2017. Seam properties of ultrasonic welded multilayered textile materials, Journal of Industrial Textiles, 46(5), 1193-1211.

[7] Reddy, R. K., 2007. Ultrasonic Seaming Of Pet, Pet/Cotton Blend And Spectra Fabrics, Yüksek Lisans Tezi, Eastern Michigan University, Michigan.

[8] Boz, S., Erdoğan, M. Ç., 2011. Ultrasonik Enerjinin Konfeksiyon Sanayiinde Kullanımı, Tekstil ve Konfeksiyon, Yıl: 21 Sayı: 1, 91-96.

[9] AK, F. N., 2006. Belirli Doku Konstrüksiyonlarının Kumaş Performans Özelliklerine Etkisi, Yüksek Lisans Tezi, Cukurova Üniversitesi Fen Bilimleri Enstitüsü, Adana.

[10] TS EN ISO 6330, 2012. Tekstil Deneyleri İçin Ev Tipi Çamaşır Makinesi İle Yıkama ve Kurutma İşlemleri.

[11] TS EN ISO 13935-1, 2014. Tekstil Kumaşların ve hazır tekstil eşyaların dikiş çekme özellikleri - Bölüm 1: Şerit yöntemi kullanarak dikiş kopması için azami kuvvetin tayini.

[12] TS 393 EN ISO 13938-1, 2002 Kumaşların Patlama Özellikleri Bölüm 1: Patlama Mukavemetinin ve
Patlama Gerilmesinin Tayini İçin Hidrolik Metot.

[13] TS 1409, 1973. Dokunmuş Tekstil Mamullerinin Eğilme Dayanımı. 